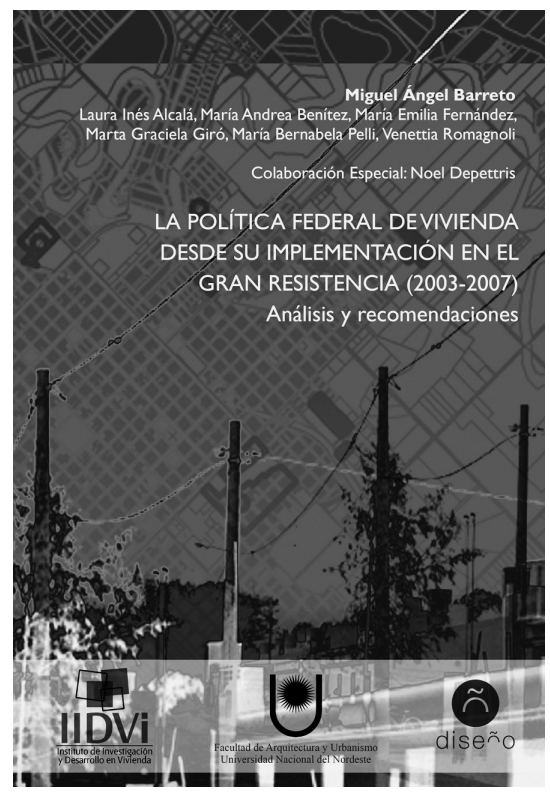

\title{
LA POLÍTICA FEDERAL DE VIVIENDA DESDE SU IMPLEMENTACIÓN EN EL GRAN RESISTENCIA (2003-2007). Análisis y recomendaciones
}

Miguel Ángel Barreto, Laura Inés Alcalá, María Andrea Benítez, María Emilia Fernández, Marta Graciela Giró, María Bernabela Pelli y Venettia Romagnoli. 2014. Editorial Diseño, Ciudad Autónoma de Buenos Aires, 332 páginas.

\section{Por Silvina López}

Arquitecta. Docente de la Facultad de Arquitectura y Urbanismo de la UNNE. Investigadora del centro de Geociencias Aplicadas de la UNNE.

Este libro presenta una investigación realizada por los integrantes del equipo de investigación del Instituto de Investigación y Desarrollo en Vivienda de la Facultad de Arquitectura y Urbanismo de la UNNE, cuyo objeto fue el estudio de la Política Federal de Vivienda, a partir de su implementación durante el período 20032007 en el Área Metropolitana Gran Resistencia (AMGR).

El trabajo, que se desarrolla en cinco capítulos, presenta en el capítulo 1 la introducción, los encuadres teórico y metodológico, los fundamentos y la organización de la metodología de investigación.

El encuadre teórico a partir del cual se definieron y valoraron las variables sigue una secuencia metodológica que se inicia con las cuestiones relacionadas con la concepción del problema, presenta en segundo lugar a los destinatarios de las soluciones habitacionales y, finalmente, las cuestiones relacionadas con las soluciones habitacionales propiamente dichas.

Es destacable el marco conceptual a partir del cual se definieron las variables con las que se analiza la implementación de la Política Federal en el AMGR, que presenta desarrollos 
del equipo de investigación en las distintas metas de las dimensiones del problema para las soluciones habitacionales de una política habitacional integral.

En el título "Las soluciones habitacionales", en relación con la integralidad que el problema demanda, los autores proponen el concepto "Hábitat Digno" como respuesta multidimensional a la cuestión, e incluyen a la vivienda junto con otros factores que en conjunto hacen un mínimo deseable de nivel de calidad de vida de los hogares.

En el capítulo 2 se sitúan las condiciones locales iniciales de implementación de la Política Federal y se caracteriza claramente el contexto de aplicación.

Los autores realizan una reseña histórica del proceso de conformación del Área Metropolitana, un continuo urbano entre los municipios de Resistencia, Barranqueras, Fontana y Puerto Vilelas, identificada como unidad de estudio y planificación y reconocida jurídicamente desde 1979.

En ese proceso identifican tres fases, y reconocen las formas de producción de suelo urbano prevaleciente en cada una de ellas haciendo énfasis en las consecuencias que esas formas de producción trajeron aparejadas, tales como los cambios de localización de los sectores sociales en el espacio urbano y las ocupaciones de tierras que dieron origen a las villas y asentamientos.

En el marco de un territorio con alta vulnerabilidad hídrica, se describen las condiciones urbano-ambientales y la situación social y habitacional del AMGR presentando los indicadores del Censo Nacional de Población y Vivienda de 2001, que agudizados con la crisis 2001-2002 configuraron en el inicio del período analizado una situación socioeconómica seriamente comprometida. Estos datos son muy relevantes, considerando que en materia de vivienda, el AMGR era en 2001 uno de los centros urbanos más deficitarios, así como la provincia del Chaco lo era a nivel nacional.

En el análisis específico de las áreas de "villas y asentamientos", los autores definen a estas áreas como una de las expresiones más críticas de la pobreza y la marginación urbana, y plantean una distinción entre ambos tipos de ocupación informal. Por otra parte, ante la falta de información tanto a nivel municipal como de los organismos provinciales (solo existían registros parciales de los asentamientos existentes), debieron realizar estimaciones propias que permitieron una aproximación a la cantidad de habitantes que en 2003 se 
encontraban viviendo en villas y asentamientos en el AMGR, en las peores condiciones de carencia de infraestructura, servicios domiciliarios y acceso al espacio público.

El trabajo analiza en el capítulo 3 la Política Federal a nivel nacional y su aplicación en la provincia del Chaco, considerando para ello las normas vigentes que definieron el marco jurídico del período, la nueva estructura organizativa de la Política Federal (con la creación del Ministerio de Planificación Federal, Inversión Pública y Servicios), la articulación de recursos financieros, los instrumentos operativos utilizados según el origen de sus formulaciones y de los recursos y, finalmente, el alcance de las soluciones implementadas.

Al nivel de análisis de la política, los autores rescatan en los nuevos programas la búsqueda de articulación de la solución de la dimensión habitacional con aspectos de las dimensiones económicas y sociales: la inversión como componente de la reactivación de la economía y creación de puestos de trabajo, impulsando la regularización del sector del trabajo y articulando con el sector desocupado y las organizaciones sociales. Por otro lado, destacan negativamente la escasa preocupación por la dimensión territorial-ambiental, reflejada en la desatención de la problemática de acceso al suelo y de la política urbana.

La implementación de la Política Federal de Vivienda en el AMGR que se presenta en el capítulo 4 es evaluada a partir el estudio de programas aplicados por el Instituto Provincial de desarrollo Urbano y Vivienda del Chaco (IPDUV). A tal efecto, fueron seleccionados tres programas creados en el período analizado, orientados a los sectores sociales en situación de pobreza y representativos de los distintos tipos de acciones implementadas.

El estudio en profundidad fue realizado sobre un proyecto de cada programa, tomando para ello la implementación del Programa Federal Solidaridad Habitacional en el B. ${ }^{\circ}$ Chelliyí, del Programa Federal Emergencia Habitacional en el B.$^{\circ}$ Vargas II y del Programa Federal Mejoramiento de Viviendas Mejor Vivir en el B. ${ }^{\circ}$ Villa Itatí.

El análisis de los casos, siguiendo la secuencia metodológica propuesta, permite ver claramente las particularidades de cada uno, así como realizar comparaciones en cada uno de los aspectos. En este sentido, es muy interesante el reconocimiento de las dimensiones para las soluciones habitacionales de una política habitacional integral, en los componentes de las soluciones habitacionales de cada programa, lo que permite avanzar en la evaluación de la integralidad de las respuestas a la problemática habitacional. 
En las conclusiones de la investigación, en el capítulo 5, se reconocen tanto los cambios favorables en la política, como también un conjunto importante de problemas en su implementación, sobre cuya base finalmente se presentan recomendaciones. Estos valiosos aportes pueden contribuir con el abordaje más integral de la problemática habitacional, así como con las modalidades de intervención y sus instrumentos, y fundamentalmente con la mayor integración de sus destinatarios.

El libro presenta un análisis sistemático y muy bien documentado, pero fundamentalmente un decidido posicionamiento de los investigadores respecto de la concepción de vivienda social, del problema habitacional para los sectores de bajos recursos, y de una política habitacional que aporte a la resolución integral del hábitat desde la perspectiva de la inclusión social. 
CUADERNO URBANO es una publicación científica con arbitraje internacional dirigida a la difusión de artículos y ensayos que se ocupan desde las disciplinas científicas de la cuestión urbana - en el sentido más amplio del término-, combinando trabajos de caracteres empíricos, teóricos y ensayísticos que den cuenta de problemáticas locales, regionales y universales. Las intenciones de la publicación son favorecer y promover la generación de ensayos y artículos de jóvenes investigadores según las reglas de arbitraje científico, colaborando en la producción editorial de sus ideas, como también divulgar el aporte de científicos ya consagrados en su especialidad disciplinar, a través de una sección especial de fondo.

La dirección editorial recibirá las contribuciones remitidas considerando dos instancias. En la primera, analizará los aspectos formales especificados más abajo con respecto a la extensión del artículo, la tipografía, el cuerpo, el interlineado, la bibliografía, etcétera; mientras que en la segunda, considerará la pertinencia del contenido, la estructura y su claridad expositiva. En esta instancia, la Dirección Editorial podrá aceptar, rechazar o sugerir cambios sobre el artículo puesto a consideración. En este último caso - de mediar acuerdo con el autor - este deberá realizar las enmiendas necesarias y reenviar el artículo al comité editorial para su reconsideración.

Una vez aceptados los trabajos, serán enviados a dos evaluadores del comité arbitral de la publicación o seleccionados entre académicos de reconocida capacidad en el tema que trata el artículo y a un tercero que dirimirá si existen opiniones opuestas entre ambos.

Una vez recibidas las evaluaciones, el comité editorial hará saber al autor los resultados mediante un dictamen unificado, guardando las reservas adecuadas. Las evaluaciones se harán por pares ciegos (autores y evaluadores se mantienen anónimos entre sí).

Una vez aceptado el artículo, la fecha de su publicación queda a criterio de los directores editoriales en función del orden de recepción y la pertinencia del tema en el contexto general de la publicación de cada número. En todos los casos, la dirección editorial comunicará al autor el número de la publicación en el que saldrá su contribución.

Los trabajos deberán ser inéditos y una vez enviados los autores se comprometerán a no presentarlos a otra publicación.

No se publicará más de un trabajo por autor, ya sea individual o en coautoría. 